\title{
The VAlue of Solar Photovoltaics in an ISOLATED COMPETITIVE ELECTRICITY MARKeT: A CASE STUdy OF Singapore
}

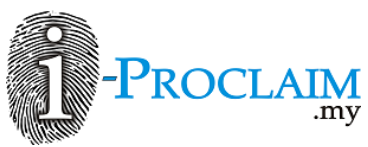

Asia Pac. j. energy environ.

\section{Anton Finenko, Gautam Jindal, Anthony D Owen*, Jacqueline Tao, Liu Xiying}

Energy Studies Institute, National University of Singapore, 29 Heng Mui Keng Terrace, Block A \#10-01, 119620, SINGAPORE

*Email for Correspondence: esiadow@ nus.edu.sg

Manuscript Received: 15 March 2020

Revised: 27 May 2020

Accepted: 25 June 2020

Key words

Solar photovoltaics, value, Singapore, merit order, frequency control services

This article is is licensed under a Creative Commons Attribution-NonCommercial 4.0 International License.

Attribution-Non Commercial (CC BY-NC) license lets others remix, tweak, and build upon work non-commercially, and although the new works must also

acknowledge \& be non-commercial.

\section{INTRODUCTION}

Singapore does not have indigenous resources of fossil fuels and its energy sector relies entirely on imports. At the same time, Singapore is "alternative energy disadvantaged", i.e. there is no technical potential to develop significant wind, tidal, wave, or geothermal power. Development of nuclear power is not considered a safe option considering the small size of the island and its high population density. Thus, distributed solar photovoltaics (PV) is currently the only viable option for Singapore to generate low carbon electricity and reduce the climate change impact of its power generation sector.

A high penetration of PV in the power sector can result in a number of costs and benefits that need to be quantified in order to ensure prudent government policies for "supporting" the widespread adoption of a variable renewable energy (VRE) technology like PV. Thus, there is limited value in relying on the levelised cost of electricity (LCOE) as a metric for evaluating the unit cost of alternative power generation technologies in a liberalized electricity market. The purpose of this study is to quantify the costs and benefits from a high penetration of PV in Singapore's electricity market. This includes quantifying the savings due to the merit order effect and net avoidance of $\mathrm{CO} 2$ emissions, offset by costs to ensure grid reliability while dealing with PV uncertainty and variability.

The paper begins with a very brief literature survey of studies of the market benefits of VRE integration in competitive electricity markets, followed by a brief outline of the National Electricity Market of Singapore (NEMS). The data sets used in the analysis are then presented. There follows a detailed discussion of the set of methodologies used to estimate the value of PV specifically for application in the context of Singapore's isolated competitive electricity market. We study three counterfactual scenarios of installed PV capacity - $600 \mathrm{MW}, 1 \mathrm{GW}$, and $2 \mathrm{GW}$, in 
Singapore's power system in the year 2014. This is followed by a description of the results. The paper concludes with a discussion of the results and their policy implications for Singapore.

This study is unique in that it uses utility price-quantity bidding behavior to reflect market demand during each 30minute market trading interval, as opposed to utilizing an economic dispatch model which requires assumptions regarding market behavior of participants which may be questionable. In addition, both recorded and theoretical solar radiation data are used, thus providing a check on whether 2014 was a representative year for the study in terms of climatic conditions. Thus the study also has relevance for liberalized power markets outside of Singapore.

\section{LITERATURE REVIEW}

To date, there have been few efforts to estimate the economic (or societal) value of investment in PV, and those that exist have tended to focus purely on its levelised cost of electricity compared with alternative electricity generation technologies (see, for example, IRENA, 2015). One reason is the complexity of PV generation and its temporal and locational variability and unpredictability. Another is that electricity industry economics are also highly complex with the value of electricity varying by time and location according to varied and uncertain energy user preferences, the mix of generation technologies, and network requirements. There is also the range of environmental and societal costs and benefits that are associated with the external impacts of power generation. Consequently, assessments of the economic value of PV tend to be limited in scope and context specific, including factors such as the match of PV generation to existing electricity demand and network capacities at different points in the grid, the electricity market and network expenditure arrangements in place within that industry, and prevailing government environmental policies. Despite these challenges, such assessments could play a valuable role in determining the case for PV support, and designing support policies such as feed-in-tariffs to maximize the economic value that PV can provide society in general. However, there is no consensus on how such economic valuations should be undertaken including what costs and benefits should be included (which is particularly problematic with regard to externalities) and how they might be estimated.

Essentially, the costs and benefits of PV in terms of its overall value to society can be evaluated in terms of six components:

- Generation capacity benefits;

- Transmission and distribution costs and benefits;

- Market price benefits;

- Energy security benefits;

- Environmental benefits; and

- Grid reliability costs.

Literature covering these components is reviewed in the following sub-sections.

\section{Generation capacity benefits}

PV systems provide generation capacity benefits in the sense that PV deployment leads to the avoided cost of building and maintaining conventional power plants. The fraction of a PV system's capacity that can reliably be used to offset conventional capacity is measured by the "capacity credit". Studies have estimated that the capacity credit for PV can be anywhere between 10 and 95 per cent, depending upon a number of factors such as the physical location of the PV plant which influences the timing and variability of solar generation, and its correlation with load (Baker et al., 2013). For example, a high PV penetration over a small geographic area, in systems with a broad portfolio of conventional generation assets, generally yields low capacity credit estimates.

However, in Singapore's case, there is already a substantial oversupply of conventional generation capacity and therefore, for the purpose of this study, we assume there are no plans for further capacity additions in the short term. Thus, benefits from avoided capacity additions are excluded from this study.

\section{Transmission and Distribution Costs and Benefits}

Distributed PV systems lead to cost savings in transmission and distribution (T\&D) as they typically relieve the requirement to supply some or all load at a particular location. Therefore, they can effectively reduce the need for additional T\&D capacity to strengthen the network that would have otherwise been necessary to cater for the increased load. However, costs are expected to be incurred for upgrading other power system elements such as transformers, voltage regulation devices and, especially, protection equipment to handle any reverse flows. 
Estimating the costs and benefits due to impacts on the T\&D network requires extensive understanding of the existing network. At the same time, modelling the network to a reasonable level of accuracy is a highly complex and time-consuming activity and requires extensive data collection. For Singapore, such detailed information about the T\&D network is not publicly available and, therefore, quantifying T\&D costs and benefits is treated as beyond the scope of this study.

\section{Market Price Benefits}

Significant deployment of distributed PV systems reduces the load in the energy market and can potentially lead to a reduction in wholesale electricity prices. This is known as the merit order effect.

The merit-order effect describes the change in the market clearing price caused by a change in supply and demand conditions in a wholesale electricity market. In the context of many integration studies conducted for renewables, the merit-order effect causes a reduction in the wholesale electricity price when a new generation source with a relatively low short run marginal cost (SRMC) is added to the grid. In practical terms, however, the merit-order effect can be caused by any short-term supply or demand intervention and is not unique to the context of renewable energy.

However, the beneficiaries of the merit-order effect are not always easy to identify. For example, even though VRE has caused a reduction of peak electricity prices over recent years in Germany, it did not have a significant impact on local consumer retail tariffs. Some important implications in the context of this study can be inferred from publications by McConnel et al. (2013) and Hirth (2013). They concluded that the merit-order effect (and closely related "value" of PV) was higher during hours of peak demand and associated high power prices, but that its impact decreased as VRE capacity grew and the opportunities for peak price shaving therefore became limited. This was particularly the case with PV, in contrast to wind, since peak electricity prices often coincide with high demand during sunny days. Further, Hindmann et al. (2015) observed that the merit-order effect can also affect the day-ahead electricity market in a similar way to its effect on the instantaneous market.

Since all PV installations in Singapore are small scale roof-top, it is assumed that the output of all distributed PV systems can be aggregated and subtracted from total market demand. Thus, integrating more PV effectively reduces electricity demand in the power system and moves the demand curve towards the left. The merit-order effect can then be measured by comparing the two systems, one without PV integration (called the reference system), and the other after integrating PV.

\section{Energy Security Benefits}

To that extent gas imports will be reduced with increased installation of PV capacity there will be energy security benefits. However, these are difficult to quantify and are likely to be significant only at high levels of installed PV capacity. Thus, these benefits are not included in the analysis.

\section{Environmental Benefits}

Environmental benefits of PV include avoided emissions of pollutants which are often monetized. Carbon dioxide (CO2) is the most commonly studied emission since the power generation sector is covered under almost all carbon taxation and emission trading schemes around the world. The magnitude of the carbon tax or the price of a carbon credit on a market essentially gives a financial value to each tonne of emissions saved and is often used, incorrectly, as a surrogate for the damage cost of $\mathrm{CO} 2$ (Owen, 2004). Over ten years since their inception, carbon prices in the European Union Emissions Trading Scheme (EU ETS) were around €7.60 per tonne of CO2-e at the end of November 2017. At their peak, emissions certificates were priced around €30 per tonne of CO2-e. Clearly, therefore, there is a great deal of uncertainty concerning the financial benefits of $\mathrm{CO} 2$ reduction.

Unlike $\mathrm{CO} 2$ emissions which have a fixed global impact irrespective of their source, emissions of air pollutants like sulphur oxides (SOx), nitrous oxides (NOx) and particulate matter (PM) mainly affect the health of the local and regional population, crops, buildings, waterways, etc. The emission rates of these pollutants depend on many variables such as fuel type, emission control technologies, heat rate, and plant vintage. The dispersion pattern of these air pollutants requires extensive modelling to identify concentrations at receptor points, and methodologies for subsequent estimation of health and other damage costs are subject to large uncertainties. In general, renewable energy integration studies do not quantify the damage costs of air pollutants, as they are very specific to the receptor area. However, in the case of Singapore, they are likely to be negligible given that the power generation sector operates almost exclusively on gas. Thus, only benefits from avoided $\mathrm{CO} 2$ emissions are included in this study. 


\section{Grid Reliability Costs and Benefits}

The intermittency and variability of PV at hourly and daily time scales can result in increased cycling and load following requirements for other dispatchable generators. As the penetration of PV increases, cycling and load following may not be restricted to just intermediate and peaking units such as gas turbines; even base load units such as coal based generators may have to operate with such requirements. Frequent on/off and steep ramping can lead to fatigue on various parts of a generating plant due to thermal stress, thus raising the cost of repair and maintenance, and increasing the chances of additional capital expenditure in case of irreparable damage.

Studies conducted by the National Renewable Energy Laboratory (Denholm et al., 2014), as part of its Western Wind and Solar Integration Study, have found that cycling costs are expected to reduce the "value" of wind and solar by between US\$0.06 and US\$2.00 per MWh at high wind penetration levels, which is a very small percentage of the total value of wind. The majority of the cold starts could be addressed through Gas - Auto Derivative Combustion Turbines whereas most of the ramping could be met by combined cycle gas turbine (CCGT) plants. As Singapore's power generation fleet is almost exclusively comprised of CCGT plant that demonstrate high flexibility in their output, we assume that the resulting cycling costs from high penetration of PV in Singapore will also be a minor component in the overall calculation of the value of PV. Thus, this cost is excluded from the scope of this study.

At shorter time scales (second, minute, and sub-hourly), the variability of PV requires additional "ancillary services" to ensure reliable operation of the grid. These include services for voltage control (through provision of reactive power) and for frequency control. While voltage control is a mandatory obligation in most power system and is generally not paid for, power system operators do procure frequency balancing services to achieve continuous and instantaneous balance between generation and load. As the penetration of PV increases, additional frequency control services are required in the system to address the generation - demand mismatch caused by the variable PV output, thus increasing the costs payable to service providers. A common conclusion from VRE integration studies is increased VRE increases the requirement for regulating reserves, whereas generally there is no additional requirement for contingency reserves. Power systems utilize regulating reserve to correct for minute-to-minute imbalances between generation and demand caused by random variation of load, whereas contingency reserves are called upon in the case of a "contingency" event such as a major generator, load, or tie-line outage.

The study mentioned above has shown that at the VRE penetration levels being examined, continuous fluctuation in wind or PV output will accentuate the fluctuations in load, and thus would require higher amounts of regulating reserve to address the imbalance. However, the sudden drop (or increase) in the wind or PV output would not be of the same magnitude as the loss of a generator (or a load), and thus the requirement for contingency reserves would be unaffected. However, some studies do estimate that the longer-term ramps caused by wind or PV may require a special category of frequency control services (FCS), generally called "Following Reserves", in case conventional generation cannot ramp up or ramp down fast enough.

For the purpose of our study, we assume that Singapore's market would require additional regulating reserves only. Thus, costs for additional regulating reserves are included in the scope of this study.

\section{An Overview of the National Electricity Market of Singapore}

In 2003 Singapore became the first Asian country to adopt a liberalized electricity market model. Currently, the total generation capacity is $13.4 \mathrm{GW}$ with a peak demand of approximately $6.7 \mathrm{GW}$. More than $95 \%$ of generation comes from CCGT generators. The National Electricity Market of Singapore (NEMS) consists of energy, reserve, and regulation markets, all of which trade over a 30-minute interval. Regulation (i.e. "load-following") is used to cover forecast real load deviations from second-to-second, and can provide both positive and negative balancing services. Three types of reserve are procured in the reserve market: primary reserve, secondary reserve, and contingency reserve, the latter for responding to "events" such as generator outages.

The installed capacity of grid-connected PV in Singapore was 138.3MWp in mid-2017, which is about 2\% of the peak system demand. In the medium term, Singapore has set a target to raise adoption of solar power to $350 \mathrm{MWp}$ by 2020 , about $5 \%$ of the then projected demand.

The NEMS is a relatively isolated system, the only link being its transmission system with Malaysia's National Grid via two $230 \mathrm{kV}$ submarine cables with a transmission capacity of $200 \mathrm{MW}$. It is generally only used to cover emergency outages. Thus this study can be regarded as an example of the impact of increasing PV market penetration on an isolated competitive electricity market. 


\section{DATA}

\section{Solar radiation data}

Solar radiation data is the key component necessary for the estimation of PV output. Solar radiation is recorded as a part of meteorological weather observations, along with temperature, precipitation and wind, and can be obtained from weather stations. In general, solar radiation follows two cycles, the daily and the yearly cycle, both of which are predetermined by the Earth's rotation and movement around the sun. The daily cycle is much more prominent in Singapore, as everywhere along the equator, while the seasonal fluctuations in solar radiation are negligible.

For our analysis we used two sets of data. The first set was the average value of solar radiation data recorded in five Singapore National Environment Agency (NEA) weather stations for the year 2014. The interval of measurements was 1 minute. Averaging data from multiple stations allowed us to represent the solar variability across Singapore closer to what can be expected if many distributed rooftop projects generated power. The year 2014 was selected as the base year, as in that year installed PV capacity was negligible.

The second set of data was generated using Meteonorm software based on long-term average cloud data for Singapore (Meteonorm is a software developed by a private company, Meteotest, that provides irradiation data for "every place on earth"). Incorporating both measured and simulated data into our analysis has made it more robust because one set of data represents the actual solar radiation in Singapore in 2014 while the other gives a theoretical value which may be interpreted as a long-term average.

\section{Electricity Market data}

All of the major characteristics of the NEMS, such as electricity demand, generation capacity, profile of the generators, electricity market rules, etc., were assumed to be as they were in 2014. Actual generator bidding data in the NEMS was obtained from the Energy Market Company (EMC) of Singapore. The bidding data provided key information about the energy supply curve at a given point in time. The energy market data included total market demand, and the corresponding supply, in the form of price-quantity bids. The data were for every 30-minute trading interval in the wholesale market for the year 2014. Given that the impact of PV on the market is predetermined by the natural cycle of solar radiation, only data for trading periods between $7.30 \mathrm{am}$ and $7 \mathrm{pm}$ were utilized. However, this approach has a limitation, since the bidding strategy of generators in 2014 is not likely to be representative of what it would be in a system with a much higher share of PV. This limitation will be further discussed later in the paper. Had bidding data not been available, an economic dispatch model could have been used instead. However, a dispatch model has its limitations when representing the actual market behavior of generation companies because it typically assumes a perfectly competitive market where generators bid at, or close to, their SRMC. In reality, generators appear to follow profit maximization strategies that involve bids that deviate significantly from SRMC, at least for part of their output. Even in the absence of market power, generators are likely to bid parcels of output at a range of prices that reflect (from low to high) minimum technical operating efficiency level, SRMC, and rent seeking behavior.

Another limitation of using a dispatch model for the Singapore power system is based upon the fact that the majority of local power generators are CCGT with similar SRMCs. A dispatch model would represent only minimal differences in the SRMC and result in a flat supply curve due to current over-capacity in the NEMS.

\section{Methodology}

\section{Quantification of Market Price Benefits}

Since all PV installations in Singapore are small scale roof-top, it is assumed that the output of all distributed PV systems will be aggregated and subtracted from total market demand. Thus, integrating more PV reduces electricity demand in the power system and moves the demand curve towards the left. PV output is estimated from actual solar radiation and the system's performance ratio which is typically 0.76 . The merit-order effect can then be measured by comparing the two systems, one without PV integration (called the reference system), and the other after integrating PV.

In order to calculate the merit order effect for this study, the bidding data for each trading interval were ranked, from lowest to highest price. Then the price of the bid which covered the last unit of electricity demand in each trading interval was taken as the market clearing price of the reference system (P0h). Integrating PV would then change the demand and clear the market at a new price level. The total demand of such a system would be the reference demand value less the estimated PV output. The new market clearing price (P1h) is derived from the last bid covering the new level of market demand, and would of course not be higher than the reference market clearing price. The merit-order effect may then be calculated as (Senfuß et al 2008): 
$h=8760$

$\sum_{h=0.5}(0 h-1 h) * 0 h$

Where,

$\mathrm{P} 0 \mathrm{~h}=$ market clearing price of the reference system: $\mathrm{S} \$ / \mathrm{MWh}$

$\mathrm{P} 1 \mathrm{~h}=$ new market clearing price for PV capacities of $600 \mathrm{MW}, 1 \mathrm{GW}$, and $2 \mathrm{GW}: \mathrm{S} \$ / \mathrm{MWh}$

$\mathrm{D} 0 \mathrm{~h}=$ total half-hourly amount of energy supplied, MWh

\section{Quantification of Costs for additional regulating reserves}

A number of methods have been utilized in integration studies to determine the additional reserve and regulation requirements to accommodate VRE variability. These include simple methods such as linear addition of load variability with the VRE variability or geometric addition of load variability with the VRE variability, and more complex methods such as recursive convolution of the probability density distributions of these factors (Holttinen et al., 2012).

This study calculated the additional requirement for reserve by conducting a statistical analysis of load variability in the baseline case and comparing it with a statistical analysis of the Net LoadT which is calculated as the load minus the PV output at time $T$ (Holttinen et al., 2008):

Net LoadT $=$ LoadT - PV OutputT

Statistical analysis of net load requires time synchronized data for load and PV output. In this study, load data (LoadT) at 1-minute resolution was generated from the demand data at 30-minute resolution in three steps (Figure 1). First, a linear trend was drawn from the demand data between time $T$ and time $T+30$ (shown as the straight line in Figure 1). Second, a series of stochastic data was generated to represent the load fluctuations. Finally, LoadT was obtained by combining the two sets of data.

Figure 1: A sample of load data generated at 1-minute resolution

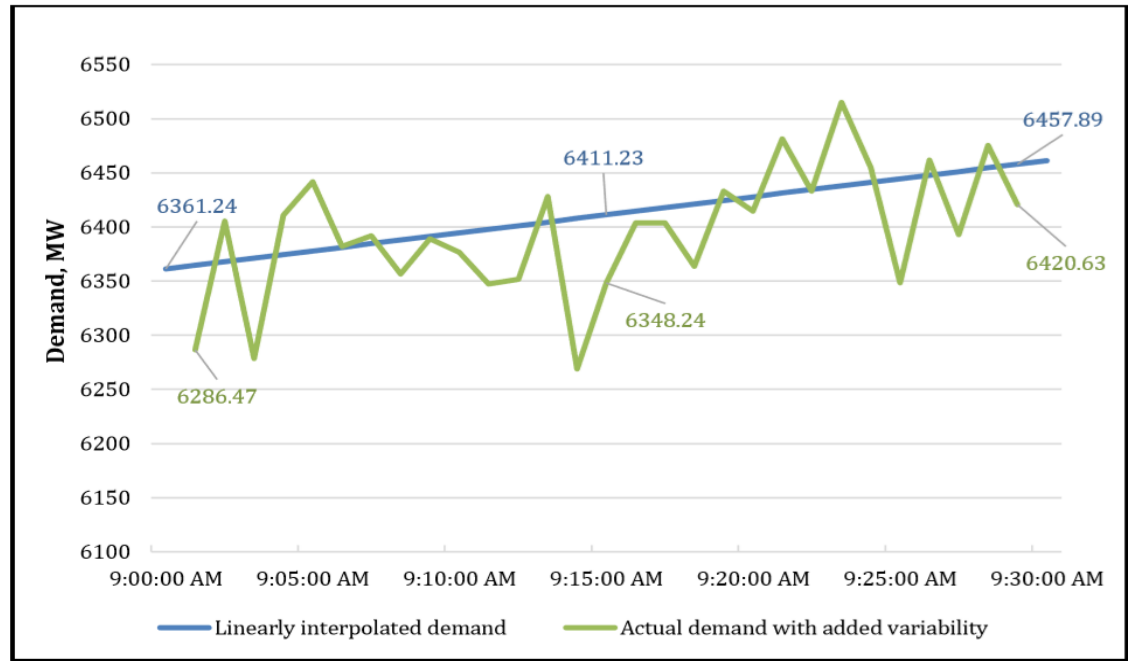

For the second step, the stochastic data were generated based on the purchased amount of regulation service. In the NEMS, the regulation service is used for continuously balancing load variations (IN 2014, the installed capacity of gridconnected PV in Singapore was 33.1MWp, which is assumed to be too small to have any significant impact on the regulation requirement) within very short periods of time. Therefore, we assume that the 1-minute load variability (Load $\mathrm{T}+1-$ $\left.\operatorname{Load}_{\mathrm{T}}\right)$ throughout the year follows a standard normal distribution $N(\mu, \sigma)$, with zero mean $(\mu)$ and standard deviation $(\sigma)$ determined by the amount of purchased regulation. Regulation is assumed to be able to cover $99 \%$ of load variation, thus it is equal to $\mu \pm 2.58 \sigma$. In 2014, the average purchased amount of regulation was $94 \mathrm{MW}$, and thus the standard deviation is equal to $36.5 \mathrm{MW}$. Then a $\mathrm{N}(0,36.5)$ series of stochastic data was generated and added to the load data generated through linear interpolation within each dispatch interval.

The Net $\operatorname{Load}_{T}$ is thus calculated at 1-minute resolution for the year 2014 for each of the three scenarios of installed PV capacity. Next, in order to calculate the variability of the Net Load, step-changes in net-load are calculated for every minute within each dispatch interval using the following equation: 
$\Delta$ Net LoadT $=$ Net LoadT - Net LoadT-1minute

Similar analysis is conducted to assess the variability of PV output. Table 1 presents the statistical analysis of the variability of PV output and the Net Load for the three scenarios of installed PV capacity.

Table 1: Statistics of solar PV output and net load variability at 1-minute resolution

\begin{tabular}{|l|c|c|c|c|c|c|c|}
\hline & \multirow{2}{*}{$\begin{array}{c}\text { Solar } \\
\text { Radiation } \\
\left(\mathbf{W} / \mathbf{m}^{2}\right)\end{array}$} & $\begin{array}{c}\text { Installed } \\
\mathrm{PV}- \\
600 \mathrm{MW}\end{array}$ & $\begin{array}{c}\text { Installed } \\
\mathrm{PV}- \\
1 \mathrm{GW}\end{array}$ & $\begin{array}{c}\text { Installed } \\
\mathrm{PV}- \\
2 \mathrm{GW}\end{array}$ & $\begin{array}{c}\text { Installed } \\
\mathrm{PV}- \\
600 \mathrm{MW}\end{array}$ & $\begin{array}{c}\text { Installed } \\
\text { PV }- \\
1 \mathrm{GW}\end{array}$ & $\begin{array}{c}\text { Installed } \\
\text { PV }- \\
2 \mathrm{GW}\end{array}$ \\
\hline Average & 0.004 & 0.002 & 0.003 & 0.007 & 0.767 & 0.78 & 0.814 \\
\hline $\begin{array}{l}\text { Standard } \\
\text { Deviation }(\sigma)\end{array}$ & 30.031 & 13.694 & 22.824 & 45.647 & 61.507 & 64.236 & 75.797 \\
\hline $\begin{array}{l}\text { Maximum } \\
\text { (positive) }\end{array}$ & 352.08 & 160.55 & 267.58 & 535.16 & 301.025 & 353.073 & 557.192 \\
\hline $\begin{array}{l}\text { Maximum } \\
\text { (negative) }\end{array}$ & -372.47 & -169.85 & -283.08 & -566.15 & -266.928 & -344.579 & -608.73 \\
\hline
\end{tabular}

\section{Environmental Benefits}

Avoided CO2 emissions from PV are estimated as a product of PV output in MWh estimated in Section 5.1 and the CO2 emission grid factor in Singapore, listed by the Energy Market Authority (EMA 2015). Since over 95 per cent of all electricity generated in Singapore in 2014 was from gas-fired CCGTs, this approach should be reasonably accurate. The price of avoided carbon dioxide emissions, generally referred to as the "social cost of carbon", was set at US\$30/tonne CO2-e. This figure aligns with that calculated by Nordhaus (2017).

\section{RESULTS AND Discussion}

\section{Merit order effect}

Figure 2 illustrates the daily merit-order effect that could have been realised if $2 \mathrm{GW}$ of PV capacity were available on 18 February 2014. The analysis has been performed based upon the NEA data, as no significant differences between NEA and Meteonorm were noted at an aggregated level.

Figure 2: Daily merit order effect in Singapore's wholesale electricity market

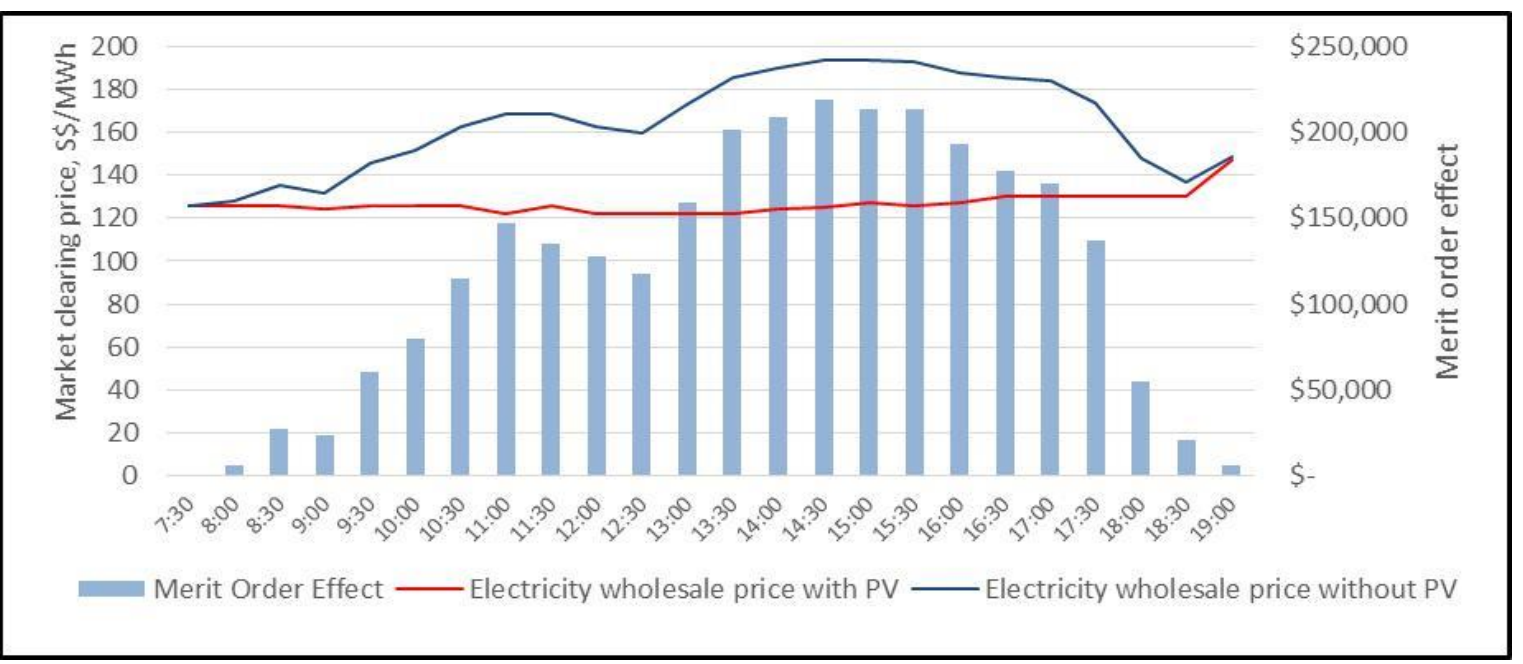

It can be observed that PV would reduce the peak market clearing prices throughout the day. Most reductions would be realized when PV output and total system demand were high, which corresponds to the highest observations of the merit-order effect. 
The set of charts in Figure 3 show the potential impact of PV supply on market clearing prices for the three scenarios based upon the NEA data. The Meteonorm data produced very similar results. Sporadic spikes in the yearly charts indicate a high merit-order effect - this is when high market clearing prices and high total system demand could be reduced by PV. As expected, the merit-order effect becomes more pronounced with an increasing share of PV in the system. This is well illustrated by the height of the data bar around mid-June which increases as the PV capacity increases from $600 \mathrm{MW}$ to $2 \mathrm{GW}$. The maximum value of the merit-order effect, or the potential system savings, could amount to around \$S2 million in any one 30-minute interval.

Figure 3: Merit order effect for the three PV penetration scenarios for 2014 (S\$)
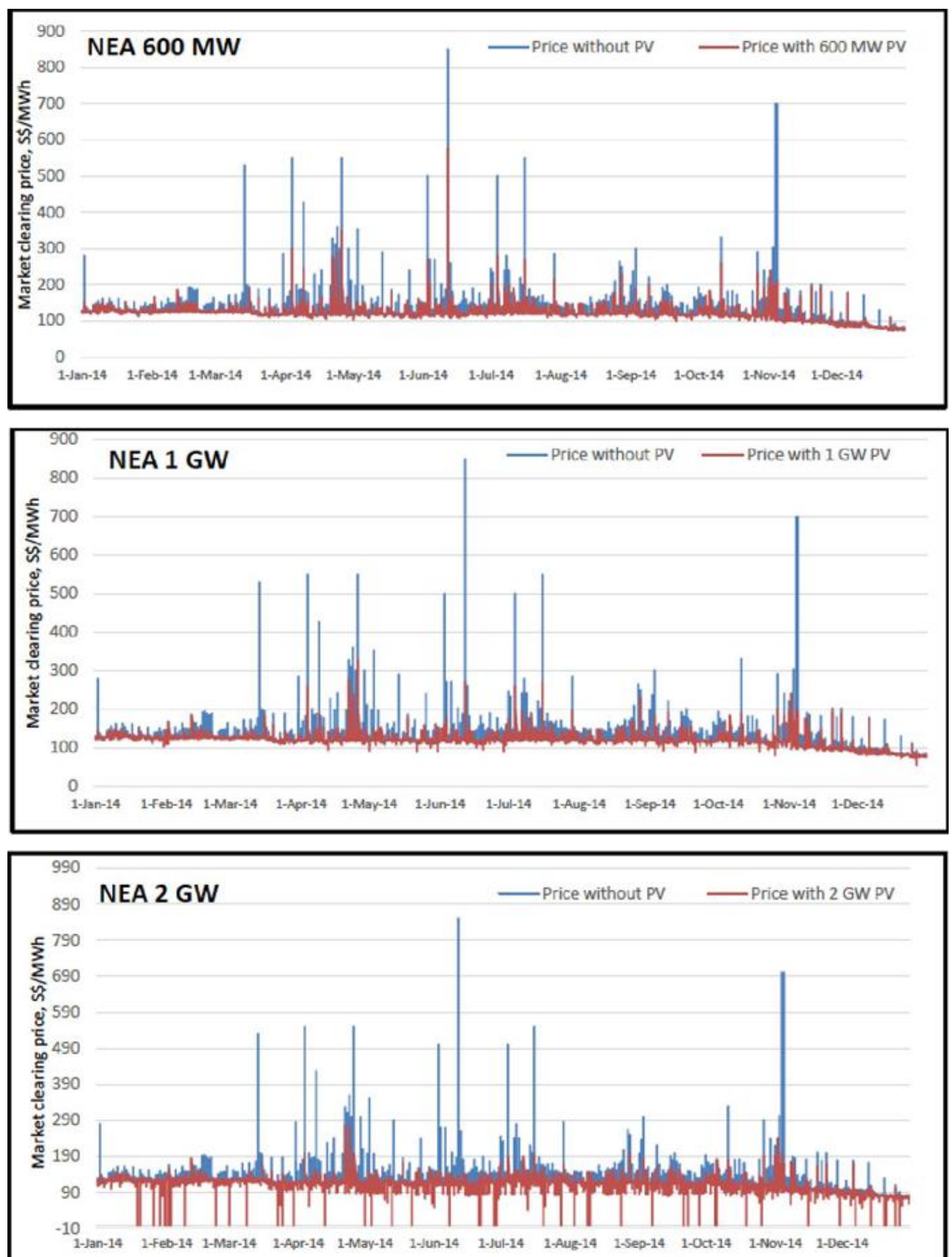
Aggregated potential merit-order values for 2014 are shown in Table 2. Total yearly monetary savings due to the merit-order effect would be between approximately $\$ \$ 380$ million and $\$ \$ 680$ million, depending on the PV capacity scenario. If we relate these numbers to the total PV generation achieved, it would give us values between $\mathrm{S} \$ 0.510 / \mathrm{kWh}$ and $\mathrm{S} \$ 0.274 / \mathrm{kWh}$. The corresponding values using the Meteonorm data are of a similar magnitude.

Table 2: Summary of merit order analysis results

\begin{tabular}{|l|l|l|l|l|l|l|}
\hline & \multicolumn{3}{|c|}{ NEA } & \multicolumn{3}{c|}{ Meteonorm } \\
\hline PV capacity scenario & $\mathbf{6 0 0}$ MW & 1 GW & 2 GW & 600 MW & 1 GW & 2 GW \\
\hline $\begin{array}{l}\text { Total yearly merit-order } \\
\text { effect, S\$million }\end{array}$ & 379.8 & 463.4 & 679.7 & 362.4 & 451.8 & 723.1 \\
\hline $\begin{array}{l}\text { Merit order effect per } \\
\text { kWh solar PV, S\$/kWh }\end{array}$ & 0.510 & 0.373 & 0.274 & 0.488 & 0.365 & 0.292 \\
\hline $\begin{array}{l}\text { Yearly merit order as \% } \\
\text { of all energy payments } \\
\text { 2014 }\end{array}$ & 5.95 & 7.37 & 10.8 & 5.77 & 7.19 & 11.5 \\
\hline $\begin{array}{l}\text { Average new market } \\
\text { clearing price, S\$/MWh }\end{array}$ & 120.34 & 117.23 & 108.77 & 120.99 & 117.64 & 107.03 \\
\hline $\begin{array}{l}\text { Average reduction of } \\
\text { market clearing price, } \\
\text { \$MWh }\end{array}$ & 13.95 & 17.07 & 25.53 & 13.32 & 16.66 & 27.27 \\
\hline
\end{tabular}

These values are significantly higher than values reported in other studies for other parts of the world. The reason for this could be the fact that other studies did not have access to bidding data and used historical information on market clearing prices or the SRMC of various generation technologies, many of which have lower SRMCs than CCGT.

An important observation arising here is the occurrence of negative wholesale prices in the system. Negative prices are unlikely to persist in reality because the real system is not static and incumbent generators would react to persistent negative wholesale price by offering less capacity or even completely withdrawing generation plant. This would reduce the available supply in the system and put upward pressure on the wholesale price, ultimately restoring market equilibrium at positive price levels.

\section{Savings in $\mathrm{CO} 2$ emissions}

The extent of the environmental benefits of renewable energy are determined by the environmental characteristics of the displaced fossil fuel. Clearly, avoided emissions are higher if coal power plants are displaced as compared with CCGT plants. Studying temporal and spatial characteristics of the power source and using marginal emission rates is the appropriate methodology for analysing such benefits in large systems. However, in the case of Singapore, the current fuel mix consists almost exclusively of CCGTs. Thus, using the average grid emission factor for Singapore can be justified.

A carbon cost of US\$30/tonne CO2 was used, which translates to S\$39.54 at the average 2014 US\$/S\$ exchange rate quoted by the US Internal Revenue Service.

The results are summarized in Table 3. It can be seen that PV can yearly offset between approximately 322 thousand tonnes and 1,075 thousand tonnes of $\mathrm{CO} 2$ for the NEA data over the range of the three scenarios, with the Meteonorm data yielding very similar results. The resulting monetary savings would be between approximately $S \$ 13$ million and $S \$ 43$ million per year.

Table 3: Benefits of avoided CO2 from PV

\begin{tabular}{|c|l|l|l|l|l|l|}
\hline & \multicolumn{3}{|c|}{ NEA } & \multicolumn{3}{c|}{ Meteonorm } \\
\hline & $600 \mathrm{MW}$ & $1 \mathrm{GW}$ & $2 \mathrm{GW}$ & $600 \mathrm{MW}$ & $1 \mathrm{GW}$ & $2 \mathrm{GW}$ \\
\hline $\begin{array}{c}\text { PV generation } \\
\text { Million MWh }\end{array}$ & 0.74 & 1.24 & 2.28 & 0.72 & 1.24 & 2.48 \\
\hline $\begin{array}{c}\text { Avoided CO2 } \\
\text { Thousand tonnes }\end{array}$ & 322.5 & 537.4 & 1074.8 & 321.8 & 536.3 & 1072.6 \\
\hline $\begin{array}{c}\text { Value of avoided } \\
\text { CO2 } \\
\text { S\$ millions }\end{array}$ & 12.75 & 21.25 & 42.50 & 12.72 & 21.21 & 42.41 \\
\hline
\end{tabular}




\section{Impact on market clearing price}

Whenever a certain portion of demand is offset by PV generation, the market clearing price will fall compared to the zero PV scenario, with the magnitude of the price reduction being determined by the steepness of the supply curve and the PV output in that particular trading period. An interesting observation is that at the 2 GW PV penetration level the market clearing price could drop to 0 on many occasions.

The potential impacts that PV could have had on marginal electricity prices in 2014 is given in Table 4. Average price reduction levels are very similar for NEA and Meteonorm data with between S\$13.95/MWh and S\$25.5/MWh and between $\$ \$ 13.32 / \mathrm{MWh}$ and $\mathrm{S} \$ 27.27 / \mathrm{MWh}$ respectively. It should be noted, however, that these values are likely to be higher during peak demand hours.

Table 4: Calculation of regulation requirement

\begin{tabular}{|c|c|c|c|c|c|c|}
\hline \multirow[b]{2}{*}{$\begin{array}{l}\text { Cause of } \\
\text { imbalance }\end{array}$} & \multicolumn{2}{|c|}{$\begin{array}{c}\text { Installed PV } \\
600 \mathrm{MW}\end{array}$} & \multicolumn{2}{|c|}{$\begin{array}{c}\text { Installed PV } \\
1 \text { GW }\end{array}$} & \multicolumn{2}{|c|}{$\begin{array}{c}\text { Installed PV } \\
2 \text { GW }\end{array}$} \\
\hline & $\begin{array}{l}\text { Net load } \\
\text { variability }\end{array}$ & $\begin{array}{l}\text { Forecast } \\
\text { error }\end{array}$ & $\begin{array}{l}\text { Net load } \\
\text { variability }\end{array}$ & $\begin{array}{l}\text { Forecast } \\
\text { error }\end{array}$ & $\begin{array}{l}\text { Net load } \\
\text { variability }\end{array}$ & $\begin{array}{l}\text { Forecast } \\
\text { error }\end{array}$ \\
\hline $\begin{array}{l}\text { Standard } \\
\text { Deviation }(\sigma) \\
(\mathrm{MW})\end{array}$ & 61.51 & 26.54 & 64.24 & 44.23 & 75.80 & 88.47 \\
\hline $3 \sigma(\mathrm{MW})$ & 184.52 & 79.62 & 192.71 & 132.70 & 227.39 & 265.41 \\
\hline $\begin{array}{l}\text { Instances covered } \\
\text { by } 3 \sigma\end{array}$ & $99.67 \%$ & $98.46 \%$ & $99.68 \%$ & $98.46 \%$ & $99.11 \%$ & $98.46 \%$ \\
\hline $\begin{array}{l}\text { Regulation } \\
\text { requirement per } \\
\text { trading interval }\end{array}$ & \multicolumn{2}{|c|}{ 264.14 MW } & \multicolumn{2}{|c|}{ 325.41 MW } & \multicolumn{2}{|c|}{ 492.80 MW } \\
\hline $4 \sigma(\mathrm{MW})$ & 246.04 & 106.16 & 256.96 & 176.92 & 303.2 & 353.88 \\
\hline $\begin{array}{l}\text { Instances covered } \\
\text { by } 4 \sigma\end{array}$ & $99.99 \%$ & $99.46 \%$ & $99.97 \%$ & $99.46 \%$ & $99.81 \%$ & $99.46 \%$ \\
\hline $\begin{array}{l}\text { Regulation } \\
\text { requirement per } \\
\text { trading interval }\end{array}$ & \multicolumn{2}{|c|}{$352.2 \mathrm{MW}$} & \multicolumn{2}{|c|}{ 433.88 MW } & \multicolumn{2}{|c|}{$657.08 \mathrm{MW}$} \\
\hline
\end{tabular}

An important discussion point is how realistic the results outlined here are when comparing them with an actual price reduction in the future. Besides the common uncertainties about future demand, fuel prices, and market policies, there are two potential limitations. The first one is that the merit-order analysis was based on the historical bidding behavior of power generation companies. Obviously, as more PV is added to the grid, fossil power generators will adapt their bidding in order to secure dispatch.

However, the manner in which bidding behavior would change is difficult to predict. It can be argued that from the generators' perspective, the merit-order effect is deferred revenue and the way to minimize it is to flatten the supply curve of own bids. However, during times when PV is unable to generate power, the bidding manner could be more aggressive in order to maximize profits.

The second limitation stems from a comparison of PV integration scenarios to a zero PV static system. The results for the merit-order effect and electricity wholesale price reduction were based on this approach. In reality, distributed PV will be developed gradually and added to a system where a certain PV capacity is already integrated. Therefore, it can be argued that the effects of every capacity increment would decrease with a growing total share of integrated PV in the market.

\section{Additional Regulating Reserve requirement and cost}

Presently, the requirement of regulation in NEMS is maintained at a relatively stable level. If there were to be a significant growth of PV installed capacity, regulation demand would increase to balance the additional PV output fluctuations. Furthermore, in the absence of any special frequency control service to compensate for the errors in forecasted PV output, the regulation service would have to compensate for that as well. 
Using the statistical analysis of net load and forecast error, the regulation requirement is calculated with different multiples $(n)$ of the standard deviation of net load variability, as well as forecast errors. If the net load variability and forecast error exhibited normal distribution behavior, 3 times $n$ would statistically cover $99.7 \%$ of the instances. However, since this is not the case, the value of $n$ is chosen to cover the net load variability and forecast error with a certain level of confidence (Holttinen et al., 2012).

For $n=3$, as installed PV capacity increases from $600 \mathrm{MW}$ to $1 \mathrm{GW}$, and then to $2 \mathrm{GW}$, regulation requirement increases to 264.14 MW, 325.41 MW and 492.80 MW respectively. The $n=3$ method is able to cover more than 99 per cent of instances of net load variability and about 98.46 per cent of the solar radiation forecast error. To cover an even higher percentage of instances, $n$ can be increased to 4 which requires higher regulation purchase to 352.2 MW, 433.88 MW and 657.08 MW for the three scenarios, respectively. In which case the percentage of instances covered by regulation rises to $99.46 \%$ (see Table 4 ).

The resultant costs of procuring the additional regulation are calculated based on the regulation requirements. Both the total cost of regulation for a year and the cost per unit of electricity generated from PV capacity are estimated. We assume that each $\mathrm{kWp}$ of installed PV capacity in Singapore generates 1250 units of electricity in a year, thus with $600 \mathrm{MW}, 1 \mathrm{GW}$, and 2GW PV installed capacity, and the annual electricity generated is $750 \mathrm{GWh}, 1250 \mathrm{GWh}$, and $2500 \mathrm{GWh}$ respectively.

Although there is an absence of publicly available data on bidding behavior for regulation requirements, an annual average is published by the Energy Market Company (EMC). In 2014, the average market clearing price for regulation was S\$33/MWh, the lowest cost for five years (EMC, 2014). The following year it fell to S\$18/MWh, rising to S\$20/MWh in 2016. In the absence of any indication of higher costs in the future, given the high level of surplus capacity in the market, the figure of $S \$ 20$ was used to generate the results for regulation costs for the three PV scenarios. Taking the $3 \sigma$ method as an example, the total regulation cost per year lies between $\$ \$ 46$ million to $\$ \$ 86$ million. However, the average cost decreases from $S \$ 0.06 / \mathrm{kWh}$ to $\mathrm{S} \$ 0.04 / \mathrm{kWh}$. These results show that higher PV integration leads to a larger total regulation costs, but a lower average regulation cost per kilowatt-hour of PV-generated electricity.

As $n=3$ is replaced by $n=4$, in the scenario of 600 MW PV capacity, the average regulation cost increases from $\mathrm{S} \$ 0.06 / \mathrm{kWh}$ and $\mathrm{S} \$ 0.08 / \mathrm{kWh}$. Similarly, the costs increase as higher levels of standard deviation are covered (Table 5).

For comparison, in 2014 the Uniform Singapore Energy Price in the NEMS was S\$0.137/kWh (EMC, 2014) (The Uniform Singapore Energy Price is the quantity weighted average of prices at all off-take nodes across Singapore). Thus the cost of regulation $(\mathrm{S} \$ 0.033 / \mathrm{kWh})$ was a significant cost component for generators in that year.

Table 5: Calculation of regulation cost

\begin{tabular}{|c|c|c|c|c|}
\hline \multirow{2}{*}{\multicolumn{2}{|c|}{$\begin{array}{l}\text { Scenario } \\
\text { Average annual yield }(\mathrm{kWh} / \mathrm{kWp} \text { per year })^{1}\end{array}$}} & $\begin{array}{c}\text { Installed PV } \\
600 \mathrm{MW}\end{array}$ & $\begin{array}{c}\text { Installed PV } \\
1 \text { GW }\end{array}$ & $\begin{array}{c}\text { Installed PV } \\
2 \text { GW }\end{array}$ \\
\hline & & \multicolumn{3}{|c|}{1,250} \\
\hline \multicolumn{2}{|c|}{ PV electricity generation in 1 Year $(\mathrm{MWh})$} & 750,000 & $1,250,000$ & $2,500,000$ \\
\hline \multicolumn{2}{|l|}{ Cost of Regulation (S\$/MWh) } & 20 & 20 & 20 \\
\hline \multirow{2}{*}{$\begin{array}{l}\text { Regulation cost for each } 30 \\
\text { minute interval (S\$) }\end{array}$} & 3-sigma & 2,641 & 3,254 & 4,928 \\
\hline & 4-sigma & 3,521 & 4,339 & 6,571 \\
\hline \multirow{2}{*}{$\begin{array}{l}\text { Regulation cost for } 1 \text { Year } \\
\text { (S\$ million) }\end{array}$} & 3-sigma & 46.3 & 57.0 & 86.4 \\
\hline & 4-sigma & 61.7 & 76.0 & 115.1 \\
\hline \multirow{2}{*}{$\begin{array}{l}\text { Cost of Regulation per unit } \\
\text { electricity generated from } \\
\text { PV Systems }(\mathrm{S} \$ / \mathrm{kWh})\end{array}$} & 3-sigma & 0.06 & 0.04 & 0.04 \\
\hline & 4-sigma & 0.08 & 0.06 & 0.05 \\
\hline
\end{tabular}

Singapore Economic Development Board, "Solar Photovoltaic (PV) Roadmap for Singapore (A Summary)". 2014 Available Online: https://www.nccs.gov.sg/sites/nccs/files/Roadmap_Solar_20140729.pdf

\section{Impact of variability over longer term}

Analyzing the step - changes of PV output and net load on a one-minute time scale is important because it gives an idea about the variability that the power system has to address within a market dispatch interval. However, if the variable energy source is expected to create an imbalance in the following dispatch interval, the dispatch instructions 
to be issued to generators at the beginning of the next trading interval can reflect the changes required to address that imbalance. Thus, the imbalance can be taken care of through normal market operations rather than relying on frequency control services. However, it is important to quantify the additional ramping burden that may be imposed on generators to address these long term changes in PV output. In the context of Singapore's electricity market, the trading interval is currently set at thirty minutes, and thus Table 6 presents the statistical analysis for demand and net load variability in 30-minute steps.

It can be seen from the Table 6 that in 2014, in the absence of PV, demand changes from one trading interval to the next are in the range $30 \pm 286 \mathrm{MW}$, i.e. between -256 to $316 \mathrm{MW}$ for $99.5 \%$ of instances. As PV deployment increases, the standard deviation of net load increases, however this increase is much smaller as compared to the increase in installed PV capacity. With $600 \mathrm{MW}$ installed PV, the change in net load only increases by $20 \mathrm{MW}$ (286 MW compared with $306 \mathrm{MW}$ ); whereas for $1 \mathrm{GW}$ installed capacity, the change in net load increases by approximately 90 MW (286 MW compared with $355 \mathrm{MW})$.

Table 6: Thirty-minute step changes in demand and net load

\begin{tabular}{|c|c|c|c|c|}
\hline & $\begin{array}{l}\text { Demand } \\
(\mathrm{MW})\end{array}$ & $\begin{array}{l}\text { Net load with } \\
600 \mathrm{MW} \text { PV } \\
(\mathrm{MW})\end{array}$ & $\begin{array}{l}\text { Net load with } \\
1 \text { GW PV } \\
(\mathrm{MW})\end{array}$ & $\begin{array}{l}\text { Net load with } \\
2 \text { GW PV } \\
(M W)\end{array}$ \\
\hline Average & 29.98 & 28.79 & 27.99 & 25.99 \\
\hline Standard Deviation ( $\sigma$ ) & 95.49 & 102.01 & 118.28 & 180.24 \\
\hline 3 x Standard Deviation & 286.48 & 306.03 & 354.83 & 540.73 \\
\hline $\begin{array}{l}\text { Instances covered by ( } 3 \\
\sigma)\end{array}$ & $99.50 \%$ & $99.29 \%$ & $99.58 \%$ & $99.45 \%$ \\
\hline Maximum (positive) & 437.48 & 443.40 & 452.67 & 848.09 \\
\hline Maximum (negative) & -406.16 & -404.92 & -515.72 & -964.93 \\
\hline
\end{tabular}

However, with 2 GW of installed PV capacity, the change in net load lies rises to $540 \mathrm{MW}$ for $99.5 \%$ cases; which is almost double the demand fluctuation without PV. Thus, this implies that the overall 30-minute ramping capacity for generation will almost need to be doubled as compared to the current ramping requirements today.

These values are larger than the maximum positive or negative ramping observed in 2014, but with Singapore's generation fleet consisting of almost exclusively CCGTs, the required rates should be achievable. For extreme cases where ramp rates are as high as $850 \mathrm{MW}$, Open Cycle Gas Turbines may have to be utilized for additional fast ramping. However, in circumstances where extremely high downward ramping is required, it is unclear whether the economically dispatched generators will be able to achieve the required ramp-down.

For other power systems, which are not as flexible as NEMS, mid-term flexibility challenges will be higher. Either more flexible technologies need to be increased in the generation mix, or less flexible generation units will have to respond faster. Both of the choices will increase the costs of integrating more variable energy and maintain the system stability and security at the same time.

\section{Conclusions and Policy Implications}

While the financial benefits and costs of PV systems are widely recognized, there is no single measure of the overall economic value they bring to society. Determining a single measure of the economic "value" of PV requires a number of costs and benefits associated with grid integration of PV to be quantified. In this study, the "value" of PV has been calculated as the sum of the savings due to the merit order effect and the reduction in CO2 emissions, offset by costs due to additional frequency control services to address PV variability.

The analysis showed that PV could achieve a total yearly merit order value in the NEMS of around 6\%, 7.3\% and $11 \%$ of the total energy payments in NEMS, according to the range of alternative GW scenarios of $600 \mathrm{MW}, 1 \mathrm{GW}$, and $2 \mathrm{GW}$. This would amount to an average reduction of market clearing prices between $\mathrm{S} \$ 0.013 / \mathrm{kWh}$, $\mathrm{S} \$ 0.017 / \mathrm{kWh}$ and $\mathrm{S} \$ 0.027 / \mathrm{kWh}$ respectively. However, it is important that policy makers interpret these results with care. The merit order effect estimates in this study are likely to be higher than that they would be in reality. This is because the magnitude of the merit order effect is predominately influenced by the bidding behavior of CCGT 
generators. As the merit order effect in the wholesale energy market is potentially deferred revenue for CCGT generators, with increased PV penetration these generators are likely to change their bidding strategy to lower the extent of the merit order effect. The merit order effect can be lowered if the supply curve becomes less steep. Therefore, the merit order effect can theoretically be decreased by CCGT generators adjusting their bidding behaviour without lowering the average market clearing price, although this may be interpreted as not re-bidding in good faith. Furthermore, comparison of the benefits from a power system with and without PV may result in an exaggerated merit order effect, although such comparisons are relatively common in the literature. In reality, PV capacity is deployed gradually and every new MW of PV is added to a system where some PV capacity already exists. Consequently, the appropriate baseline for every new PV increment should be a system without that increment. In line with other studies, we would expect that every new MW of PV deployed will have a lower marginal value than its predecessor.

Statistical analysis of solar radiation forecast and variability data has shown that additional FCS services needed to be purchased to integrate larger amount of PV in Singapore. For the power system with three scenarios of PV installed capacity, corresponding additional regulation requirements were calculated as $352.2 \mathrm{MW}, 433.88 \mathrm{MW}$, and 657.08 MW, based on the 4-sigma statistical approach. The corresponding total regulation cost per year lies between $\mathrm{S} \$ 61.7$ million to $\$ \$ 115.1$ million. However, the average cost decreases from $S \$ 0.08 / \mathrm{kWh}$ to $\$ \$ 0.05 / \mathrm{kWh}$. The results show that higher PV integration leads to larger total regulation cost as installed capacity increases, yet a lower average regulation cost per kilowatt-hour PV-generated electricity. The results from FCS analysis raise important implications for small isolated systems (and grids). The majority of prevailing VRE studies analyze additional requirements of FCS for large power systems that are spread across large geographic areas and generally have a lower need for balancing. Furthermore, many of such systems are interconnected with neighboring power systems through which energy imbalances can be mitigated. In large power systems that do not have interconnections, for example ERCOT, geographical diversity may mitigate VRE variability to a large extent. However, the situation can be very different for small isolated power systems or isolated grids located within small geographic regions and with limited interconnection where VRE variability can have a much more pronounced impact.

Uncertainties in solar forecast and short-term variability of solar PV play the crucial part in determining how much additional FCS is needed to accommodate VRE. Improvements in accuracy of solar radiation forecast, by for example separating clear-sky and cloud variability, can significantly reduce the need for additional FCS deployed to accommodate forecast errors. The variable nature of solar and wind will also push technical capabilities of FCS to the limit, demanding short-term flexibility as the key parameter. Flexibility requirements will be even higher in isolated systems. However, battery storage technology may become the main provider of short-term FCS in isolated grids in the future.

Finally, given the range of wide assumptions and associated values considered in this paper, it would be misleading to attempt to calculate a single number for the "value of solar". Rather, the precision of each element must be considered in isolation and its veracity judged accordingly when aggregating them.

\section{FUNDING ACKNOWLEDGEMENT}

This work was supported by the Ministry of Trade and Industry, Government of Singapore. The authors thank experts from Solar Energy Research Institute of Singapore (SERIS) for data on solar radiation forecast.

\section{REFERENCES}

Baker, E., Fowlie, M., Lemoine, D., Reynolds, S., 2013. The Economics of Solar Electricity. Annual Review of Resource Economics. $5,387-426$.

Denholm, P., Margolis, R., Palmintier, B., Barrows, C., Ibanez, E., Bird, L., 2014. Methods for analysing the benefits and costs of distributed photovoltaic generation to the U.S. electric utility system. Technical report NREL/TP-6A20-62447.

Dumas, J., Maggio, D., 2014. Electric Reliability Council of Texas Case Study: Reserve Management for Integrating Renewable Generation in Electricity Markets, Renewable Energy Integration, Practical Management of Variability, Uncertainty and Flexibility in Power Grids. 2014, 117-124.

Energy Market Authority (EMA), 2015. Singapore Energy Statistics 2015. Available online: https://www.ema.gov.sg/cmsmedia/Publications_and_Statistics/Publications/SES2015_Final_website＿2mb.pdf. Last accessed 15 June 2016.

Energy Market Company (EMC), 2014. Market Report 2014. Available online: https://www.emcsg.com/f279,97223/NEMS_Market_Report_2014.pdf 
Hirth, L., 2015. Market value of solar power: is photovoltaics cost-competitive? IET Renewable Power Generation. 9, 37-45.

Holttinen, H., Milligan, M., Ela, E., Menemenlis, N., Dobschinski, J., Rawn, B., Bessa, R.J., Flynn, D., Gomez-Lazaro, E., Detlefsen, N., 2012. Methodologies to Determine Operating Reserves Due to Increased Wind Power. IEEE Transactions on Sustainable Energy. 3(4), 713-723

Holttinen, H., Milligan, M., Kirby, B., Acker, T., Neimane, V., Molinski, T., 2008. Using standard deviation as a measure of increased operational reserve requirement for wind power. Wind Engineering. 32, 355-378.

IEEE Transactions on Power Systems. 26, 594-603.

International Renewable Energy Agency (IRENA), 2015. Renewable Power Generation Costs in 2014.

Kondziella, H., Bruckner, T., 2016. Flexibility requirements of renewable energy based electricity systems - a review of research results and methodologies. Renewable and Sustainable Energy Reviews. 53, 10-22.

Matos, M., Bessa, R.J., 2011. Setting the operating reserve using probabilistic wind power forecasts.

McConnel, D., Hearps, P., Eales, D., Sandiford, M., Dunn, R., Wright, M., Bateman, L., 2013. Retrospective modelling of the meritorder effect on wholesale electricity prices from distributed photovoltaic generation in the Australian National Electricity Market. Energy Policy. 58, 17-27.

Nordhaus, W.D., 2017. Revisiting the social cost of carbon. Proceedings of the National Academy of Sciences of the United States of America. 114, 1518-1523.

Owen, A.D., 2004. Environmental externalities, market distortions and the Economics of Renewable Energy Technologies. The Energy Journal. 25, 127-156.

Senfuß, F., Ragwitz, M., Genoese, M., 2008. The merit order effect: a detailed analysis of the price effect of renewable electricity generation on spot market prices in Germany. Energy Policy. 36, 3086-3094. 